\title{
PENERAPAN PROTOKOL PUBLISH / SUBSCRIBE MESSAGING SYSTEM PADA SISTEM WIRELESS BUILDING NETWORK BERBASIS NRF24L01
}

\author{
Sarosa Castrena Abadi ${ }^{1}$, Anton Prafanto ${ }^{2}$, Mindit Eriyadi ${ }^{3}$, Aris Suryadi ${ }^{4}$, Givy Devira Ramady ${ }^{5}$ \\ 1,3,4Politeknik Enjinering Indorama \\ ${ }^{2}$ Universitas Mulawarman \\ ${ }^{5}$ Sekolah Tinggi Teknologi Mandala \\ Email: ${ }^{1}$ sarosa.castrena@pei.ac.id, ${ }^{2}$ antonprafanto@fkti.unmul.ac.id, ${ }^{3}$ mindit.eriyadi@pei.ac.id, \\ ${ }^{4}$ aris.suryadi@pei.ac.id, ${ }^{5}$ givy.d.ramady@gmail.com
}

\begin{abstract}
Abstrak
Wireless sensor network merupakan sebuah metode yang umum digunakan dalam sebuah perancangan infrastruktur interkoneksi sumber daya berbagi pakai pada suatu titik lokasi sehingga mampu memberikan performa yang optimal. Faktor utama dalam perancangan sebuah protokol komunikasi wireless sensor network (WSN) berupa upaya optimalisasi koordinasi antar node, salah satu upaya efektif yang dapat dilakukan untuk mencapai kondisi tersebut berupa penyediaan node yang menggunakan protokol publish / subscribe messaging system. Penelitian ini membahas mengenai penerapan protokol publish / subscribe messaging system pada sistem wireless building network berbasis NRF2L01. Pembahasan meliputi simulasi, perancangan, implementasi, pengujian aplikasi dan kinerja sistem baik secara fungsi kerja maupun performa dari setiap node. Hasil penelitian menunjukkan sistem mampu memonitor semua informasi dan mengendalikan peralatan dari suatu gedung melalui antarmuka web memudahkan petugas dalam pemeliharaan dan pengawasan suatu gedung, kemudian untuk pengujian performa node dengan ukuran paket data tetap 32 byte, nilai delay untuk setiap node kurang dari 1 detik, kemudian untuk data rate $250 \mathrm{kbps}$ throughput minimal yang diperoleh sebesar 5.9 Kbps dan throughput maksimal yang diperoleh sebesar 72 Kbps dan untuk packet loss minimal $0.59 \%$ sedangkan packet loss maksimal $13.23 \%$ dan nilai standar deviasi dari delay, throughput dan packet loss lebih kecil dari nilai rata- ratanya menunujukkan data tidak terlalu bervariasi (stabil).
\end{abstract}

Kata Kunci: WSN, IOT, Publish/Subscribe Messaging System, OPNET, NRF24L01.

\begin{abstract}
Wireless sensor network is a common method used in the design of shared resource interconnection infrastructure at a location point to provide optimal performance. The main factor in the design of a wireless sensor network (WSN) communication protocol in the form of coordination optimization efforts between nodes, one of the effective methods that can be made to achieve such conditions is the provision of nodes using the publish / subscribe messaging system protocol. This research discusses the implementation of publish / subscribe messaging system protocol on wireless building network system based on NRF2LO1. Discussions include simulation, design, implementation, application testing and system performance both on a work-to-work and performance-by-node performance. The results showed the system was able to monitor all information and control equipment from a building through a web interface making it easier for officers to maintain and supervise a building, then to test the performance of nodes with a fixed data packet size of 32 bytes, the delay value for each node is less than 1 second, then for the minimum throughput $250 \mathrm{kbps}$ data rate obtained at $5.9 \mathrm{Kbps}$ and the maximum throughput obtained at 72 Kbps and for packet loss of at least $0.59 \%$ while the maximum packet loss of $13.23 \%$ and the standard deviation value of delay, throughput and packet loss are smaller than the average value, the data is not very varied (stable).
\end{abstract}

Keywords: WSN, IOT, Publish/Subscribe Messaging System, OPNET, NRF24L01. 


\section{PENDAHULUAN}

Konsep dari suatu sistem smart building adalah integrasi dari desain bangunan maupun interior dengan jaringan terdistribusi, teknologi embedded system dan perangkat node yang digunakan baik dalam proses monitoring maupun proses kontrol kapanpun dari semua tempat (Nugroho \& Nugroho, 2020).

Smart building umumnya tepat untuk di implementasikan di satu gedung atau lebih dalam satu area seperti area industri, perkantoran ataupun institusi pendidikan (Ghayvat et al., 2015). Wireless Sensor Network merupakan salah satu metode yang tepat untuk diterapkan pada sistem smart building. Pada proses implementasi wireless sensor network salah satu faktor yang perlu diperhatikan adalah penghematan energi untuk setiap node (I. Pratama \& Suakanto, 2015). Salah satu solusi sebagai langkah penghematan energi tersebut adalah dengan penggunaan sejumlah protokol jaringan yang terkait dengan komunikasi antar node - node sensor (R. P. Pratama et al., 2017).

Sistem koordinasi antar node merupakan hal yang penting dalam merancang protokol komunikasi untuk sistem wireless sensor network (Tekin \& Sahingoz, 2016), solusi efektif untuk masalah tersebut adalah dengan menyediakan node yang menggunakan publish / subscribe messaging system , dimana node sensor mempublikasikan data yang diperoleh dengan topik tertentu, sedangkan node aktuator melakukan subscribe data atau topik tertentu yang sesuai dan menerima data untuk segera di lakukan tindakan berdasarkan data yang ada (Albano \& Chessa, 2009). Bentuk implementasi dari wireless sensor network salah satunya adalah monitoring node sensor, penerimaan data secara real time dan berbasis internet, di sinilah peranan Internet of things (IOT) pada wireless sensor network (Kumar \& Venkatesh, 2018). Internet of things (IOT) menyediakan konsep dan teknologi agar sistem wireless sensor network dapat terhubung ke Internet sehingga informasi dapat diakses dari jarak jauh melalui gadget seperti laptop, remote device, server dan sebagainya (Ramady et al., 2019).

Penelitian ini membahas mengenai penerapan protokol publish/subscribe messaging system pada wireless building network berbasis NRF24L01 (Af'idah et al., 2014). Pembahasan penelitian meliputi analisis kinerja model wireless sensor network melalui simulasi dengan menggunakan aplikasi OPNET (Astiti et al., n.d.), desain sistem, implementasi sistem, pengujian kinerja protokol publish/subscribe messaging system pada wireless building network berbasis NRF24101 (Septiano \& Gozali, 2020).

\section{METODE}

\section{Perancangan Simulasi}

Pada penelitian ini proses simulasi bertujuan untuk mengetahui prediksi mengenai jumlah node publisher yang sesuai untuk mendapatkan throughput, delay dan Packet Loss (Anggraini et al., 2014) maksimal. Hasil simulasi akan menjadi referensi sebelum proses implementasi ke sistem nyata. Proses simulasi menggunakan software OPNET, kemudian pada proses perancangan simulasi agar sistem yang dibuat dapat berjalan sesuai yang diinginkan maka diperlukan pengaturan parameter simulasi (Aravinth Raj \& Venkatesh, 2018). Untuk mempermudah dan memperjelas pengaturan parameter simulasi maka parameter simulasi akan disajikan dalam bentuk tabel dan gambar sebagai berikut.

Tabel 1 Konfigurasi Parameter Simulasi

\begin{tabular}{|l|l|}
\hline \multicolumn{1}{|c|}{ Parameter } & \multicolumn{1}{c|}{ Spesifikasi } \\
\hline Network Simulator & $\begin{array}{l}\text { OPNET Riverbed Modeler } \\
\text { Academic Edition 17.5 }\end{array}$ \\
\hline Topologi & Star \\
\hline Luas Area & $100 \mathrm{~m}^{2}$ \\
\hline Waktu Simulasi & 5 menit \\
\hline Tipe Node & Fixed \\
\hline Data Rate & $250 \mathrm{Kbps}$ \\
\hline Ukuran Paket & 38 Bytes \\
\hline
\end{tabular}

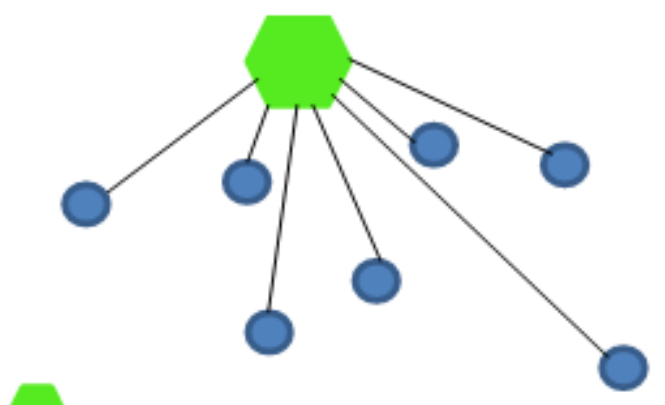

Broker

End Device

Gambar 1. Topologi Simulasi Jaringan WSN

Parameter topologi disesuaikan dengan studi kasus pada sistem wireless building network yang mana menggunakan topologi star dimana hanya ada 1 node broker yang bertindak sebagai koordinator dan beberapa node end device / client yang dapat bertindak sebagai subscriber dan sebagai publisher 
(Nuresalandis, 2017), kemudian luas area di simulasikan bahwa luas area kampus $100 \mathrm{~m}^{2}$, kemudian untuk type node dipilih fixed node karena node tersebut sifatnya statis tidak mobile (berpindah - pindah tempat). Karakteristik nyata yang terdapat pada datasheet, data rate pada NRF24L01 dapat di atur mulai dari $250 \mathrm{Kbps}, 1 \mathrm{Mbps}$ dan $2 \mathrm{Mbps}$, namun semakin besar data rate yang digunakan sensitivitas semakin rendah maka pada simulasi ini menggunakan data rate $250 \mathrm{Kbps}$, kemudian jumlah paket diatur menjadi 38 byte dikarenakan paket tersebut terdiri dari 1 byte preamble, 3 byte address, 1 byte paket kontrol, 32 byte paket data dan 1 byte paket CRC.

Pada simulasi ini skenario dimulai dengan menggunakan 1 node broker dan 1 node end device kemudian dilakukan pengiriman paket data dari node end device ke node broker dan sebaliknya. Proses terus dilanjut dengan menambah 1 lagi node end device dan terus menambah node end device sampai mendapatkan jumlah node end device yang menghasilkan throughput, delay dan Packet Loss (Anggraini et al., 2014) maksimal.

Pengaturan parameter pada node broker dan setiap node publisher untuk setiap proses simulasi sama seperti yang ditunjukkan oleh gambar 2 dan gambar 3.

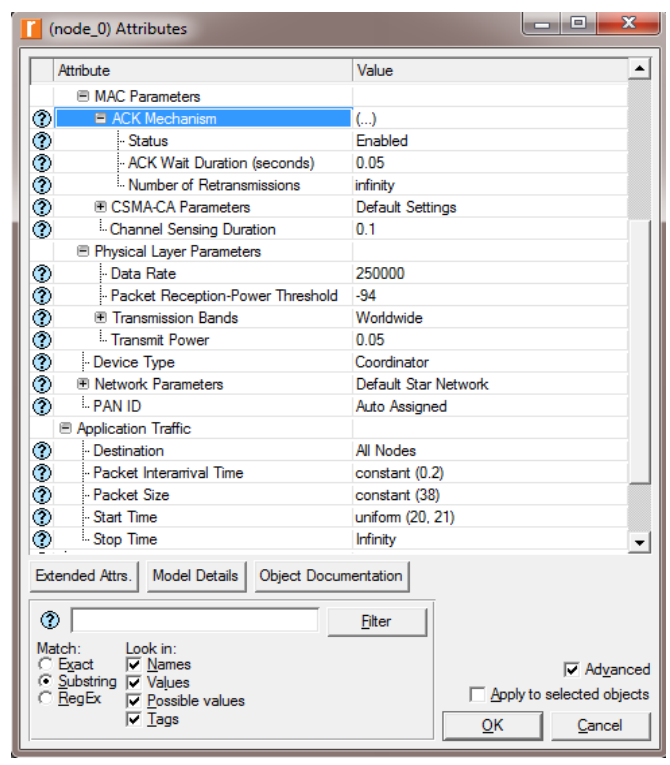

Gambar 2. Parameter Node Broker

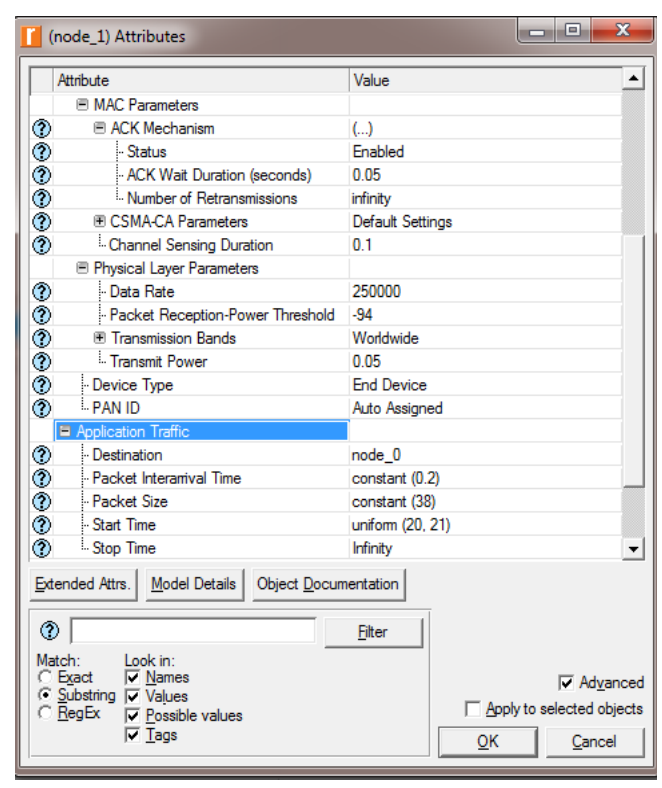

Gambar 3. Parameter Node End Device

\section{Perancangan Sistem}

Pada penelitian ini perangkat yang dirancang secara umum memiliki 4 bagian utama, yaitu:

- Broker sebagai perangkat yang menjadi perantara komunikasi antara Publisher dan Subscriber.

- Publisher sebagai perangkat yang membaca sejumlah perangkat sensor dan mentransmisikan data tersebut ke broker agar data tersebut dapat di subscribe.

- Subscriber sebagai perangkat yang mengendalikan aktuator sesuai dengan data yang diperoleh dari broker.

- Server, sebagai perangkat yang mengintegrasikan data dari jaringan privat ke jaringan publik melalui internet.

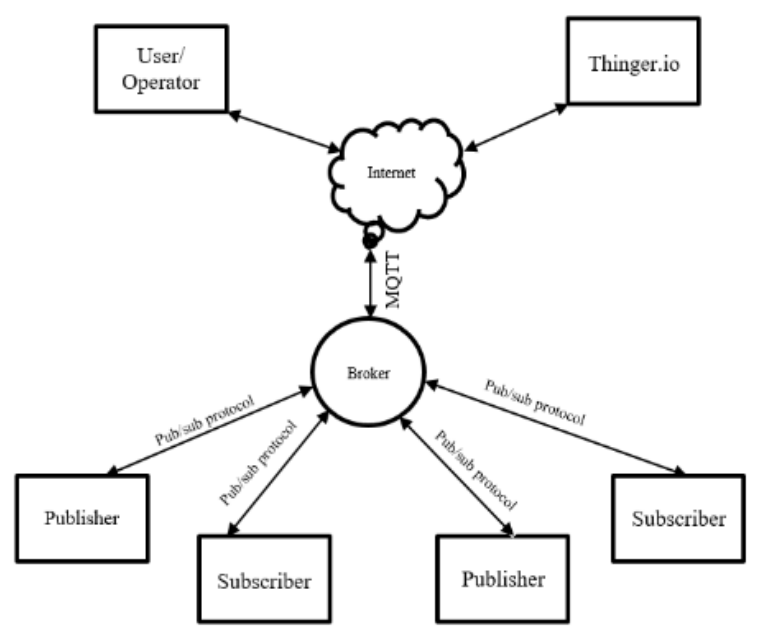

Gambar 4. Topologi Sistem 
Pada sistem ini broker diintegrasikan dengan beberapa perangkat yang meliputi node publisher yang berisi (perangkat sensor), node subscriber (aktuator) yang meminta data dari node broker, data sensor yang diperoleh publisher ditransmisikan ke broker kemudian disimpan di server dan ditransmisikan ke subscriber yang membutuhkan data sesuai topic yang subscriber butuhkan. Broker juga menerima data kontrol dari server, data tersebut akan di publish ke perangkat subscriber yang ingin di kendalikan.

Studi kasus yang digunakan dalam penelitian adalah pemanfaatan perangkat Wireless Sensor Network pada prototipe sistem monitoring dan kontrol gedung. Beberapa parameter penting yang perlu di pantau serta yang perlu diberi peringatan pada sebuah gedung, diantaranya parameter gas, parameter gerakan, perameter cahaya, parameter suhu dan kelembaban, juga parameter status volume sampah. Beberapa paremeter yang telah disebutkan memiliki peranan penting pada sistem keamanan gedung, seperti parameter gas dan parameter gerakan. Contohnya seperti peringatan terhadap gas atau asap yang umumnya dapat memicu munculnya api penyebabkan kebakaran. Selain itu parameter gerakan juga dapat digunakan untuk memonitoring ada atau tidaknya aktifitas di sebuah ruangan dan kemudian dibandingkan dengan parameter cahaya, sehingga penjaga gedung dapat memantau penggunaan lampu ruangan yang bila tidak ada aktifitas lampu tersebut seharusnya dimatikan. Kemudian parameter status tempat sampah yang menggunakan sensor ultrasonic untuk memantau penuh atau tidaknya tempat pembuangan sampah di setiap ruangan, sehingga penjaga gedung tidak perlu mengecek satu persatu tempat pembuangan sampah di setiap ruangan.

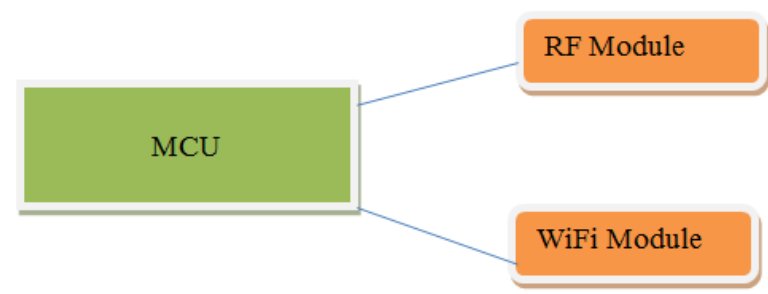

Gambar 5. Arsitektur Hardware Broker

Spesifikasi MCU yang akan digunakan pada perangkat ini menggunakan Arduino uno dan perangkat transmisi radio berfungsi untuk menerima transmisi dari publisher dan yang mentransmisikan data ke subscriber menggunakan NRF24L01, sedangkan perangkat transmisi wireless yang berfungsi untuk mengirim data ke server menggunakan Nodemcu Esp 8266 (Shobrina et al., 2018).

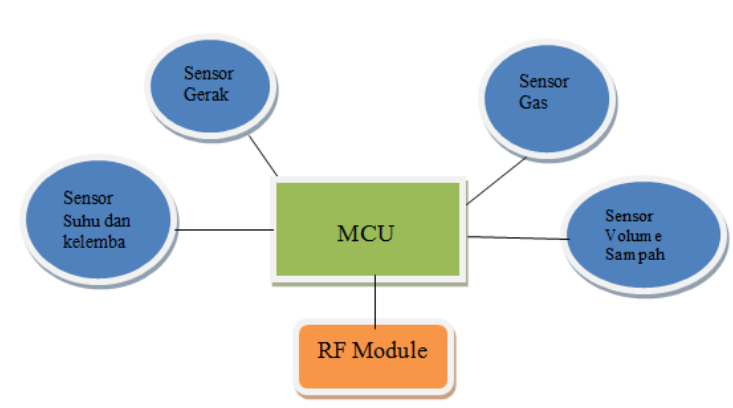

Gambar 6. Arsitektur Hardware Publisher

Spesifikasi MCU yang digunakan modul publisher dan subscriber menggunakan Arduino nano dan modul transmisi radio yang dipakai tetap sama yaitu NRF24L01, perbedaannya arsitektur.

perangkat keras publisher diintegrasikan dengan beberapa perangkat sensor yang sesuai dengan kebutuhan untuk memonitoring keadaan ruangan pada sebuah gedung.

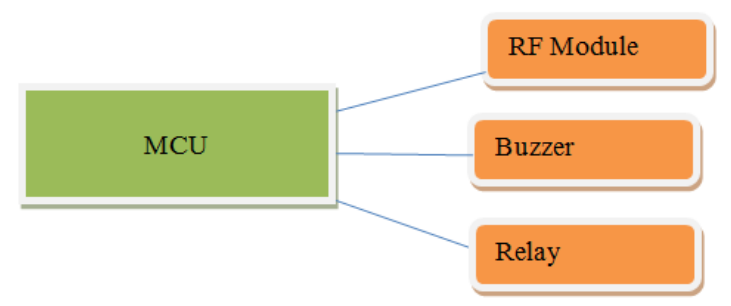

Gambar 7. Arsitektur Hardware Subscriber

Sedangkan pada modul subscriber MCU di integrasikan dengan perangkat aktuator seperti buzzer dan relay.

Tampilan antarmuka direncanakan akan dibuat dalam bentuk web menggunakan aplikasi cloud server dari thinger.io, dimana web tersebut akan memuat data sensor dan panel kontrol untuk menyalakan dan mematikan lampu. Berikut ini rencana sketsa tampilan untuk halaman antarmuka web pada sistem wireless building network.

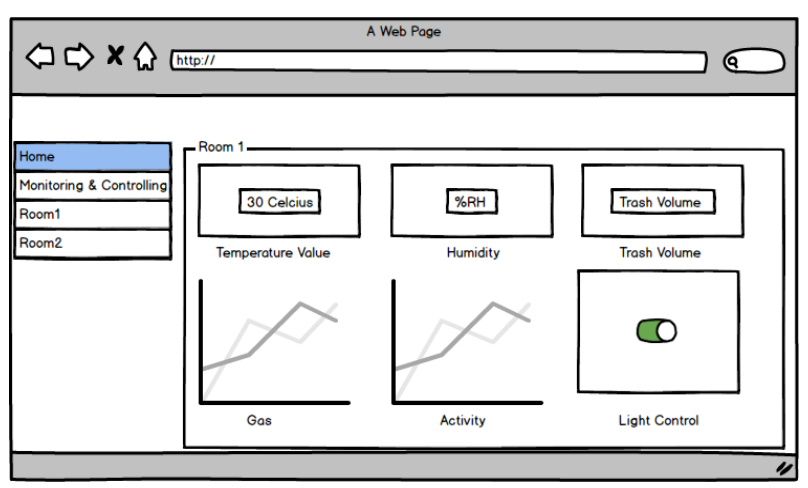

Gambar 8. Rencana sketsa tampilan untuk halaman antarmuka web pada sistem wireless building network. 


\section{HASIL DAN PEMBAHASAN}

\section{Hasil Pengujian Simulasi}

Pengujian simulasi bertujan untuk mencari jumlah node ideal yang menghasilkan throughput, delay dan packet loss terbaik untuk diimplementasikan pada sistem. Berikut grafik hasil pengujian simulasi.

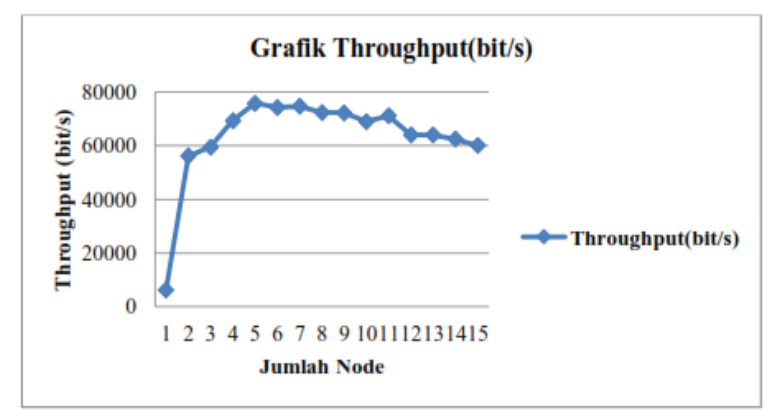

Gambar 9. Grafik Throughput Pada Broker

Berdasarkan hasil pengujian dapat diambil kesimpulan bahwa mencapai throughput maksimal yaitu sebesar $75799 \mathrm{bit} / \mathrm{s}$ atau ketika node end device / client sebanyak 5 node.

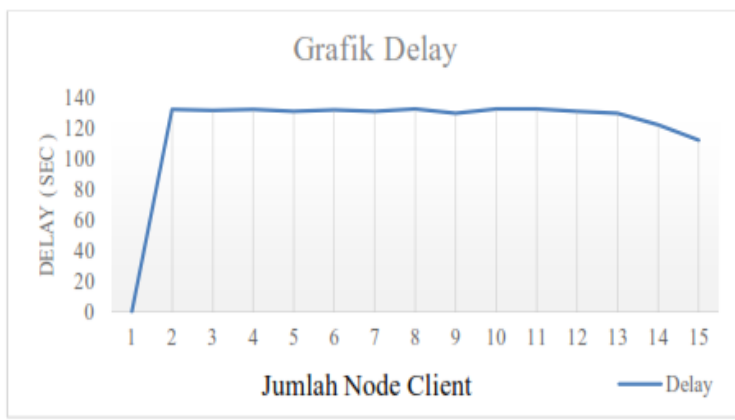

Gambar 10. Grafik Delay Pada Broker

Berdasarkan hasil pengujian dapat diambil kesimpulan bahwa delay maksimal yang dapat dicapai adalah sebesar 132,33 detik ketika jumlah node end device / client sebanyak 11 node

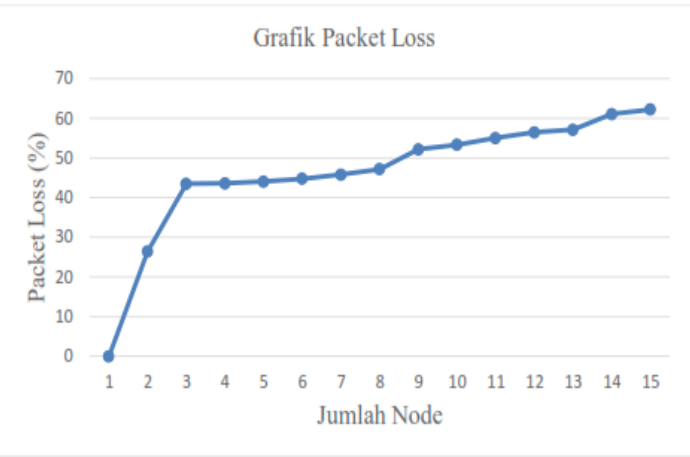

Gambar 11. Grafik Packet Loss Pada Broker
Berdasarkan hasil pengujian dapat diambil kesimpulan bahwa peningkatan packet loss berbanding lurus dengan jumlah node end device / client, semakin banyak node end device / client semakin besar juga packet loss yang terjadi

\section{Pengujian Sistem}

Pengujian sistem dimulai dengan menguji fungsi kerja aplikasi yang terdiri dari fungsi pemantauan dan kontrol, pada penelitian ini aplikasi yang digunakan untuk fungsi pemantauan dan control menggunakan aplikasi cloud server dari thinger.io dan protokol komunikasi yang digunakan untuk mengirim data dari broker ke server thinger.io yaitu protokol MQTT (Hanifah et al., 2018), berikut salah satu hasil pengujian aplikasi dan pengujian proses publisher mengirim data sensor gas ke broker untuk di subscribe oleh subscriber yang berfungsi menyalakan peringatan alarm menggunakan buzzer sebagai ditunjukkan di bawah ini.



Gambar 12. Pengujian tampilan aplikasi untuk proses menampilkan dan monitoring data dari node broker

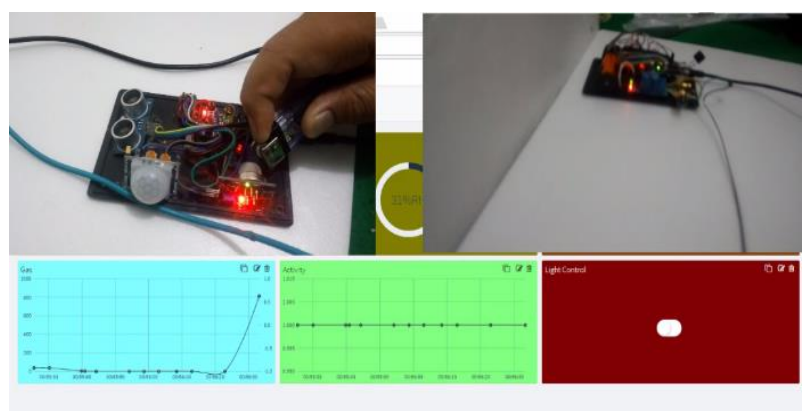

Gambar 13. Pengujian proses publisher mengirim data sensor ke broker untuk di subscribe oleh subscriber

Pengujian selanjutnya adalah pengujian performa sistem yang terdiri dari 2 skenario yaitu proses publish dari publisher ke broker dan kemudian diteruskan sampai ke server dan proses subscribe data sensor dan instruksi control dari server ke broker kemudian dilanjutkan ke subscriber. Berikut hasil pengujian performa sistem yang disajikan dalam bentuk grafik. 


\section{Pengujian Publish data}

Hasil pengujian waktu delay dari masing - masing node dengan ukuran paket tetap sebesar 32 byte dan waktu pengujian selama 5 menit nilai rata-rata delay publish data dari node publisher 1 ke broker, node publisher 2 ke broker dan broker ke server masing masing sebesar 6,6 ms, 6,3 ms dan 25,09 ms dengan standar deviasi masing - masing sebesar 1.897, 2.079 dan 1.265.

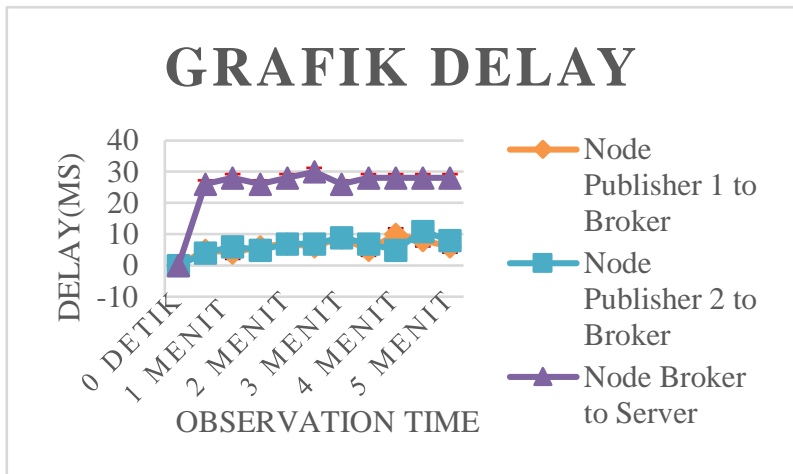

Gambar 14. Grafik delay waktu publish data dari node publisher sampai ke server

Hasil pengujian dengan ukuran paket tetap sebesar 32 byte nilai rata - rata throughput untuk proses publish data dari node publisher 1 ke broker, node publisher 2 ke broker dan broker ke server masing - masing sebesar $35 \mathrm{Kbits} / \mathrm{s}, 35 \mathrm{Kbits} / \mathrm{s}$ dan $7 \mathrm{Kbits} / \mathrm{s}$ dengan standar deviasi masing - masing sebesar 10.536, 11.548 dan 0.849

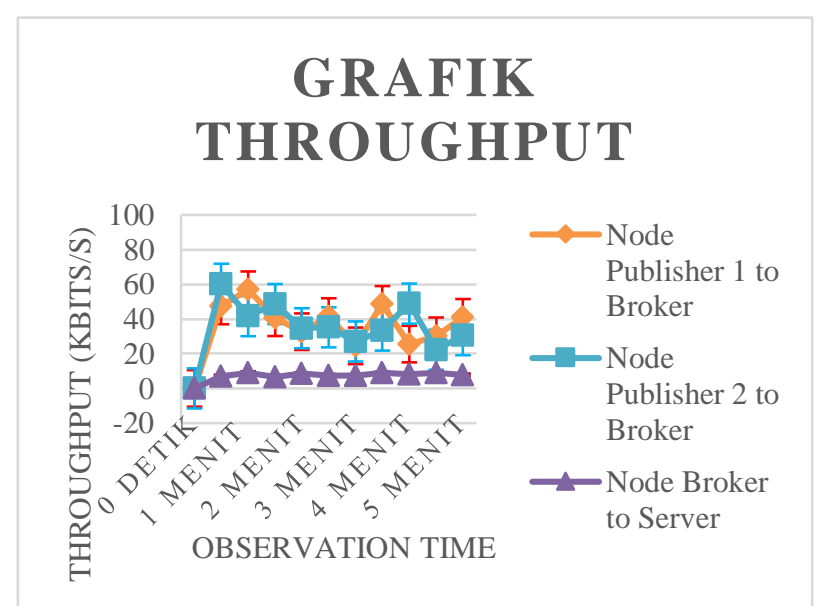

Gambar 15. Grafik Throughput publish data dari node publisher sampai ke server

Hasil pengujian dengan ukuran paket tetap sebesar 32 byte. Berdasarkan hasil pengujian rata rata packet loss untuk proses publish data dari node publisher 1 ke broker, node publisher 2 ke broker dan broker ke server masing - masing sebesar $5,92 \%, 4,43 \%$ dan 13,23\% dengan standar deviasi masing - masing sebesar 4.180, 1.680 dan 11.402 .

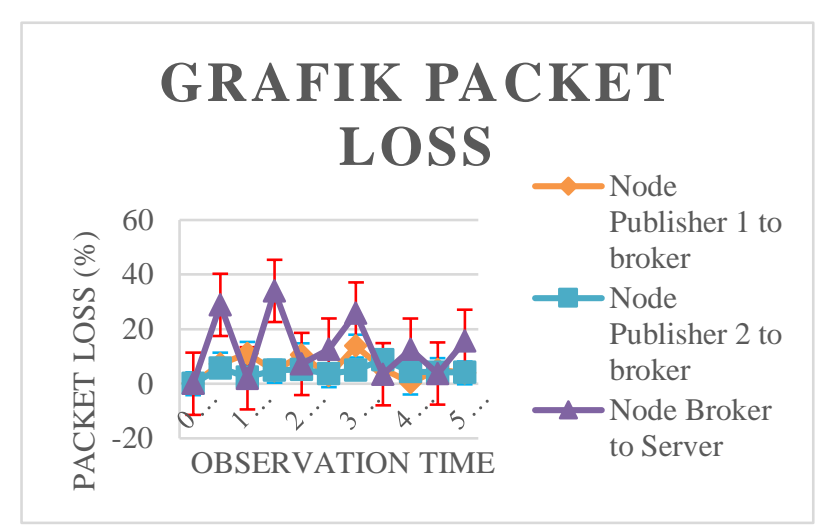

Gambar 16. Grafik Packet Loss publish data dari
node publisher sampai ke server

\section{Pengujian Subscribe Data}

Pengujian ini terdiri dari pengujian proses subscribe baik data yang di request oleh subscriber ke broker maupun data yang di request oleh broker ke server.

Hasil pengujian waktu delay dari masing masing node dengan ukuran paket tetap sebesar 32 byte dan waktu pengujian selama 5 menit nilai ratarata delay untuk proses subscribe data yang di request oleh node subscriber 1 ke node broker, subscriber 2 ke node broker dan node broker ke server masing - masing sebesar $3,36 \mathrm{~ms}, 3,55 \mathrm{~ms}$ dan $34,82 \mathrm{~ms}$ dengan standar deviasi masing masing sebesar 1.567, 1.449 dan 3.129.

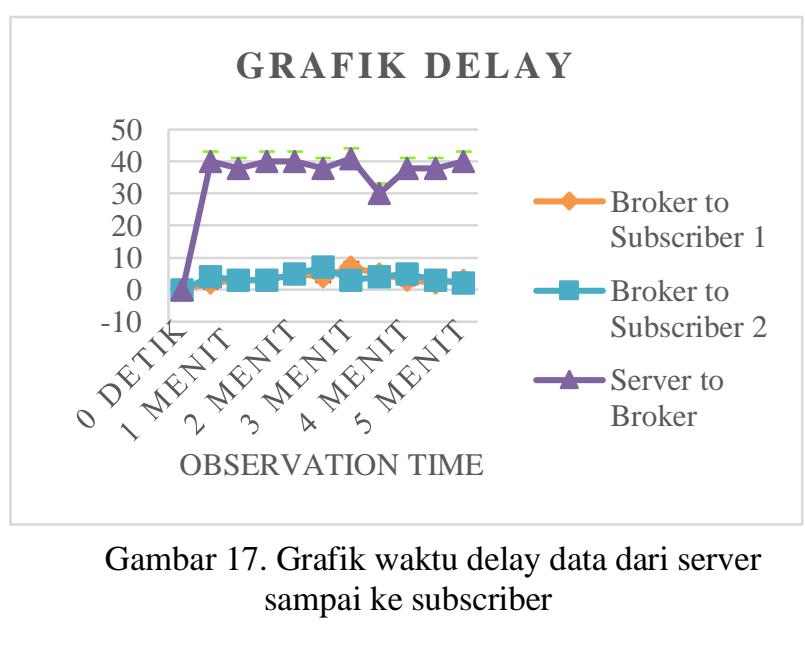

Hasil pengujian dengan ukuran paket tetap sebesar 32 byte nilai rata - rata throughput untuk proses subscribe data yang di request oleh node subscriber 1 ke node broker, subscriber 2 ke node broker dan node broker ke server masing - masing sebesar $72.01 \mathrm{Kbits} / \mathrm{s}, 66.54 \mathrm{Kbits} / \mathrm{s}$ dan $5.90 \mathrm{Kbits} / \mathrm{s}$ dengan standar deviasi masing - masing sebesar $30.379,25.865$ dan 0.668 . 


\section{GRAFIK THROUGHPUT}

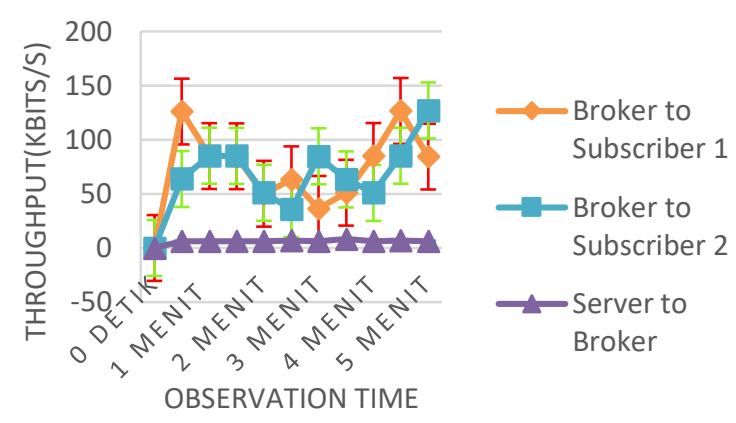

Gambar 18. Grafik throughput data dari server sampai ke subscriber

Hasil pengujian dengan ukuran paket tetap sebesar 32 byte nilai rata - rata packet loss untuk proses subscribe data yang di request oleh node subscriber 1 ke node broker, subscriber 2 ke node broker dan node broker ke server masing - masing sebesar $0,91 \%, 0.59 \%$ dan $3,24 \%$ dengan standar deviasi masing - masing sebesar 0.91, 0.59 dan 3.24.

\section{GRAFIK PACKET LOSS}



Gambar 19. Grafik packet loss data dari server sampai ke subscriber

\section{PENUTUP}

\section{Kesimpulan}

1. Sistem wireless bulding network yang berbasis NRF24L01 dengan protokol publish /subscribe messaging system mampu memonitor semua informasi dan mengendalikan peralatan dari suatu gedung secara real time melalui antarmuka web memudahkan petugas dalam pemeliharaan dan pengawasan sumber daya gedung - gedung dari jarak jauh.

2. Berdasarkan hasil simulasi nilai throughput maksimal yaitu sebesar 75799 bit/s ketika node end device / client sebanyak 5 node dan throughput cenderung menurun kembali ketika jumlah node end device / client lebih dari 5 node, hal tersebut dikarenakan semakin banyak node semakin banyak juga packet loss yang terjadi maka banyak node yang tidak berhasil mentransfer data.

3. Berdasarkan hasil simulasi delay maksimal yang dapat dicapai adalah sebesar 132,33 detik ketika jumlah node end device / client sebanyak 11 node.

4. Berdasarkan hasil simulasi peningkatan packet loss berbanding lurus dengan jumlah node end device / client, semakin banyak node end device / client semakin besar juga packet loss yang terjadi

5. Berdasarkan hasil pengujian nilai standar deviasi dari delay, throughput dan packet loss lebih kecil dari rata- ratanya maka hal tersebut menunujukkan data tidak terlalu bervariasi (stabil).

6. Berdasarkan hasil pengujian performa node dengan ukuran paket data tetap 32 byte nilai delay untuk setiap node kurang dari 1 detik, kemudian untuk data rate $250 \mathrm{kbps}$ throughput minimal $5.9 \mathrm{Kbps}$ dan throughput maksimal yang diperoleh sebesar $72 \mathrm{Kbps}$ dan untuk packet loss minimal $0.59 \%$ sedangkan packet loss maksimal $13.23 \%$ maka sistem wireless building network yang menerapkan protokol publish/subscribe dengan menggunakan NRF24101 dapat dikatakan bekerja dengan efektif dan cukup cepat.

\section{DAFTAR PUSTAKA}

Af'idah, D. I., Rochim, A. F., \& Widianto, E. D. (2014). Perancangan jaringan sensor nirkabel (JSN) untuk memantau suhu dan kelembaban menggunakan nRF24L01+. Jurnal Teknologi Dan Sistem Komputer, 2(4), 267-276.

Albano, M., \& Chessa, S. (2009). Publish/subscribe in wireless sensor networks based on data centric storage. Proceedings of the 1 st International Workshop on Context-Aware Middleware and Services: Affiliated with the 4th International Conference on Communication System Software and Middleware (COMSWARE 2009), 37-42.

Anggraini, D., Irawati, I., \& Mayasari, R. (2014). Analisis Dan Simulasi Wireless Sensor Network (Wsn) Untuk Komunikasi Data Menggunakan Protokol Zigbee. EProceedings of Engineering, 1(1).

Aravinth Raj, S., \& Venkatesh, V. (2018). Implementation of Wireless Sensor Network with Low Cost and Low Power using Arduino 
and nRF24L01. International Journal of Pure and Applied Mathematics, 119(18), 20952103.

Astiti, N., Diafari, I., \& Er, N. I. (n.d.). Analisis Pengaruh Jumlah Device Terhadap Performansi Standar Zigbee Pada Wsn Untuk Aplikasi Smart Building. Jurnal SPEKTRUM, 2(3), 79-85.

Ghayvat, H., Mukhopadhyay, S., Gui, X., \& Suryadevara, N. (2015). WSN-and IOT-based smart homes and their extension to smart buildings. Sensors, 15(5), 10350-10379.

Hanifah, S., Akbar, S. R., \& Amron, K. (2018). Implementasi Quality of Service pada Protokol Message Queue Telemetry Transport-Sensor Network (MQTT-SN) Berbasis Arduino dan NRF24L01. Jurnal Pengembangan Teknologi Informasi Dan Ilmu Komputer E-ISSN, 2548, 964X.

Kumar, C. K., \& Venkatesh, V. (2018). Cloud based soil monitoring and smart irrigation system using IoT and precision farming. International Journal of Pure and Applied Mathematics, 119(18), 2011-2020.

Nugroho, D. N., \& Nugroho, R. (2020). Penerapan Prinsip Performance-Based Smart Building Pada Perencanaan Sekolah Tinggi Multimedia Surakarta. Senthong, 3(1).

Nuresalandis, E. (2017). Rancang Bangun Low Power Sensor Node Dengan Atmega328P Berbasis NRF24l01. Universitas Brawijaya.

Pratama, I., \& Suakanto, S. (2015). Wireless Sensor Network. Bandung: Informatika.

Pratama, R. P., Akbar, S. R., \& Bhawiyuga, A. (2017). Rancang Bangun Low Power Sensor Node Menggunakan MSP430 Berbasis NRF24L01. Jurnal Pengembangan Teknologi Informasi Dan Ilmu Komputer E-ISSN, 2548, 964X.

Ramady, G. D., Hidayat, R., Syafruddin, R., Mahardika, A. G., \& Hakim, R. R. (2019). Sistem Monitoring Data pada Smart Agriculture System Menggunakan Wireless Multisensor Berbasis IoT. Prosiding Seminar Nasional Teknoka, 4, E51-E58.

Septiano, A., \& Gozali, T. (2020). Nrf 24101 Sebagai Pemancar/Penerima Untuk Wireless Sensor Network. Jurnal Tekno, 17(1), 26-34.
Shobrina, U. J., Primananda, R., \& Maulana, R. (2018). Analisis Kinerja Pengiriman Data Modul Transceiver NRF24101, Xbee dan Wifi ESP8266 Pada Wireless Sensor Network. Jurnal Pengembangan Teknologi Informasi Dan Ilmu Komputer E-ISSN, 2548, 964X.

Tekin, Y., \& Sahingoz, O. K. (2016). A Publish/Subscribe messaging system for wireless sensor networks. 2016 Sixth International Conference on Digital Information and Communication Technology and Its Applications (DICTAP), 171-176. 